\title{
Profile and Pattern of Substance Abusers: Substance Abuse, A Global Problem
}

\author{
Neelam Kotwal ${ }^{1}$, Sunil Kumar ${ }^{2}$, Monika Malhotra ${ }^{2}$, Saurabh Sadotra ${ }^{2}$, Pankaj Kumar ${ }^{3}$ and Mohammad Sarwar \\ Mir $^{3 *}$
}

${ }^{1}$ Former Medical Officer at Shri Mata Vaishno Devi Shrine Board, India

${ }^{2}$ IMO Grade 1 ESIC Hospital, India

${ }^{3}$ SKIMS Soura, India

*Corresponding author: Mohammad Sarwar Mir, SKIMS Soura, India

\begin{abstract}
Introduction: The drug abuse is the complex problem of not only of individual but also of the entire community. According to the World Health Organization (WHO) substance use is persistent or sporadic drug inconsistent with or unrelated to acceptable medical practices. Drug abuse is becoming the emerging problem in the youth which breaks back of any nation.

Methods: A cross-sectional survey was conducted during the period of January 2016 at a health camp organized by an NGO. Total 100 subjects were studied.

Results and Conclusion: In this study majority of cases were males belonging to younger age groups. Majority of the patients belonged to lower socioeconomic section. $60 \%$ of the subjects were poly substance abuser. Charas was the most commonly abused substance followed by alcohol.
\end{abstract}

Keywords: Substance abuse; Youth; Drugs

\section{Introduction}

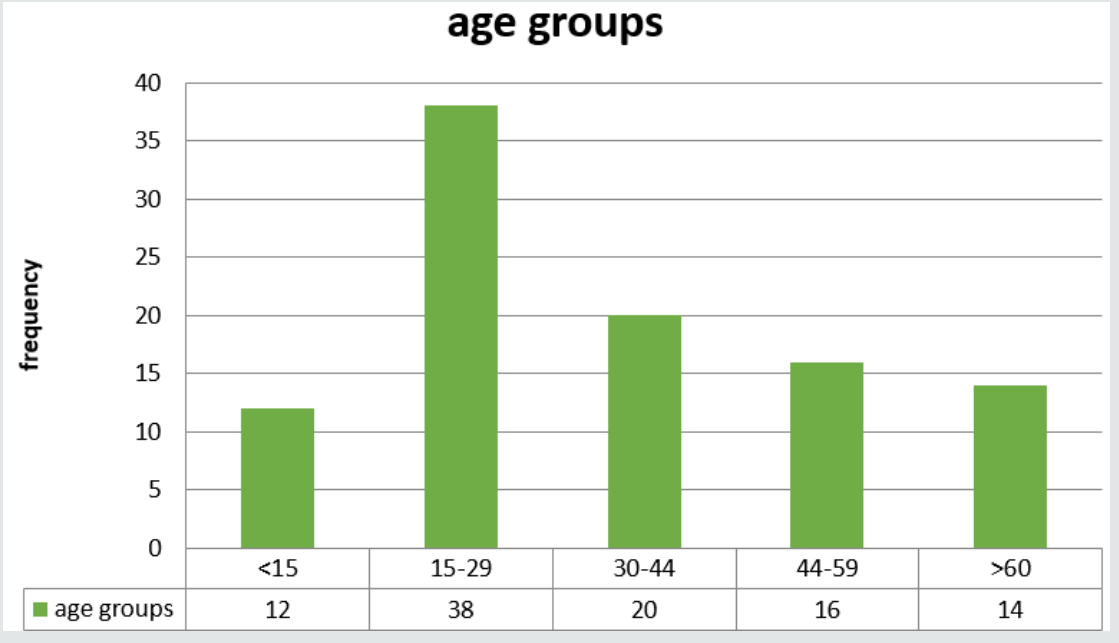

Figure 1: Age wise distribution of cases. 
The drug abuse is the complex problem of not only of individual but also of the entire community [1]. According to the World Health Organization (WHO) substance use is persistent or sporadic drug inconsistent with or unrelated to acceptable medical practices [2]. A drug is broadly defined as any chemical agent that affects living protoplasm [3]. Some drugs reinforcement i.e. they produce the effects that user enjoys, and which make him/her wish to take it again or to induce drug seeking behavior [3]. Drug addiction symptoms or behaviors (in general) includes: Feeling that you have to use the drug regularly; Failing in your attempts to stop using the drug; Spending money on the drug, even though you can't afford it; Doing things to obtain the drug that you normally wouldn't do, such as stealing; Feeling that you need the drug to deal with your problems; and Focusing more and more time and energy on getting and using the drug. Drug abuse is becoming the emerging problem in the youth (Figures $1 \& 2$ ). The profile and Pattern of drug abuse will help to understand problems and to devise strategies to deal with this global problem.

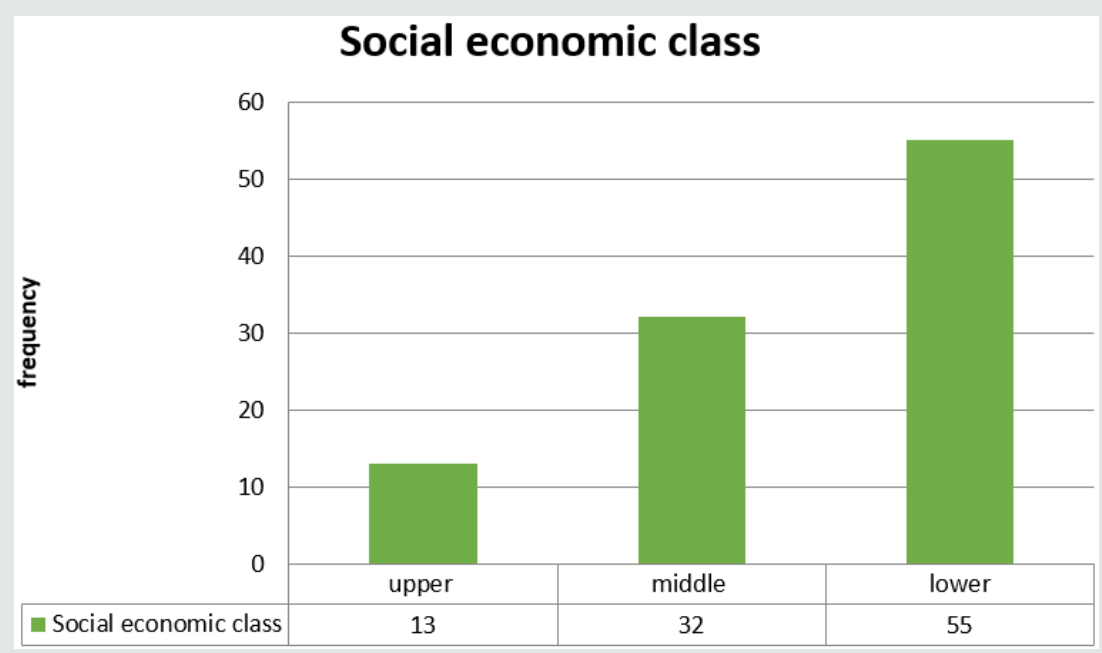

Figure 2: Socioeconomic Status.

\section{Material and Methods}

A cross sectional survey was conducted during the period of January 2016 at a suburb in Srinagar. The relevant data was collected related to profile and pattern was collected using a predesigned and pretested proforma. Data was entered in MS Excel and analyzed by using percentage and proportion wherever appropriate.

\section{Results}

The information was gathered for a total of 100 participants in the study.

\section{Discussion}

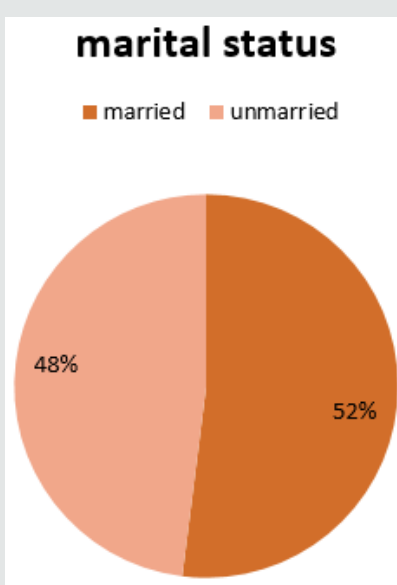

Figure 3: Marital Status.

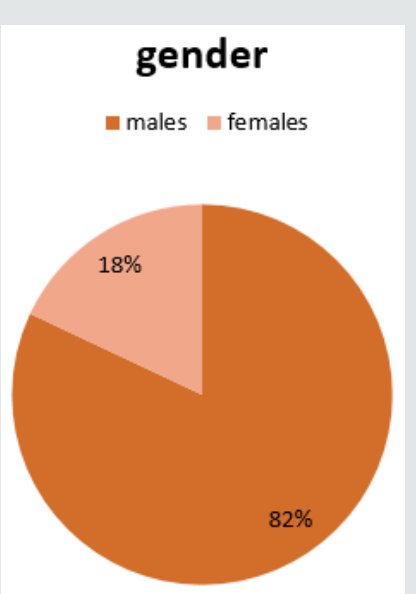

Figure 4: Gender wise distribution of cases.

The drug abuse is the complex problem of not only of individual but also of the entire community. According to the World Health Organization (WHO) substance use is persistent or sporadic drug inconsistent with or unrelated to acceptable medical practices (Figures $3 \& 4$ ). It the biggest challenge that youth have to face all over the world. In the present study, the maximum numbers of subjects were found to be age less than 40 years. The various studies $[1,5,6]$ conducted also show that maximum number of study subjects were adults aged less than 40 years. The trend is disturbing as the most productive section of society is involved in drug abuse which can have disastrous consequences. $82 \%$ of 
the subjects were males similar findings were observed in other studies $[1,4,5] .655 \%$ of the cases belonged to lower economic class. Charas was the most commonly abused substance may be because of its easy availability followed by alcohol (Figure 5).

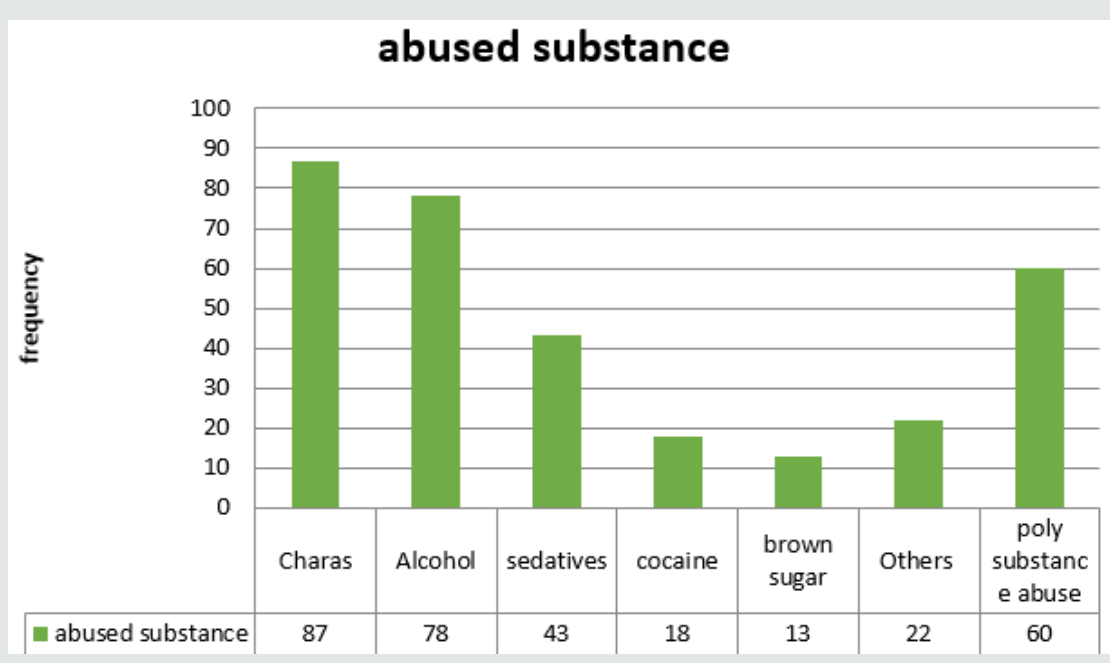

Figure 5: Distribution of cases according to substance abused.

\section{Conclusion}

In the present study maximum subjects belong to age less than 40 years, maximum belongs to the lower socio-economic class. Also, maximum subjects had consumed Charas followed by Alcohol. Thus, sociodemographic profile revealed that younger age, low socio economic status and educational background were frequent observations with drug abusers.

\section{References}

1. Jumade PP, Kasbe AM, Giri PA (2016) Socio-demographic profile of male drug abusers residing in Mumbai city, Maharashtra, India. Int J Community Med Public Health 3(5): 1115-1118.
2. WHO (1999) Techn. Res Ser No 886, pp. 48

3. Goodman and Gilman's (2011) The Pharmacological Basis of Therapeutics, $\left(12^{\text {th }}\right.$ edn.). Drug Invention and the Pharmaceutical Industry, p. 3.

4. Mayo Clinic Diseases and Condition: Drug Addiction.

5. Kumar V, Nehra DK, Kumar P, Sunila, Gupta R (2013) Prevalence and Pattern of Substance Abuse: A study from De-addiction Centre. State Institute of Mental Health, Rohtak, Delhi Psychiatry Journal 16(1): 1523.

6. Manick, Singh M (2013) Drug addiction and alcoholism in Punjab: an empirical study of a village. Political Economy Journal of India.
This work is licensed under Creative Commons Attribution 4.0 License

To Submit Your Article Click Here: Submit Article

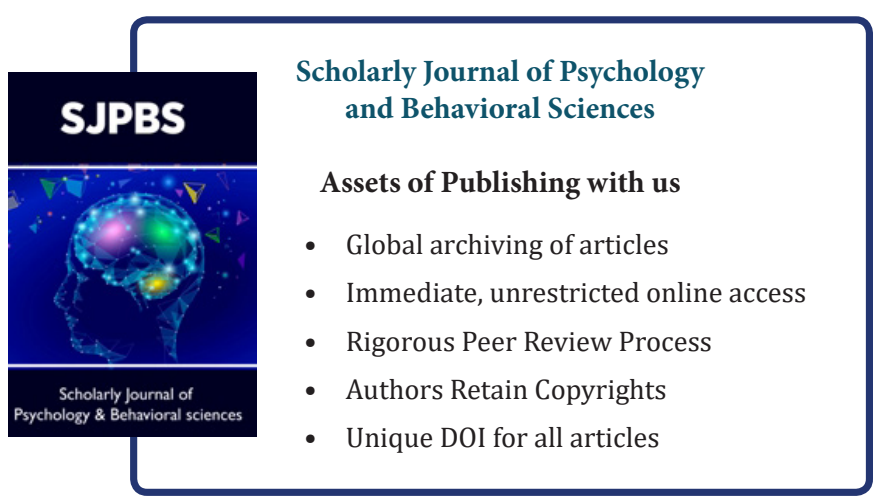

